\title{
POTENCIAL E DIVERSIDADE BIOLÓGICA DA FLORESTA NACIONAL DO IBURA, EM SERGIPE
}

\author{
Carlos Alberto Vasconcelos ${ }^{1}$ \\ Maria dos Prazeres de Araújo Nery ${ }^{2}$
}

\section{RESUMO}

A preservação e conservação da biodiversidade exigem, além da criação de mecanismos legais de gestão coletiva e participativa, ações do poder público, a exemplo da criação de Unidades de Conservação. No Brasil, são notórios o aumento de Unidades de Conservação e a extensão de áreas protegidas nas últimas décadas, nos três níveis de governo. Em Sergipe, observa-se um processo de regularização dos espaços protegidos com o intuito de proteger áreas de relevância ambiental e/ou cultural-histórica nos diversos ecossistemas do estado, apesar de ter o menor percentual de áreas de proteção integral. Há entraves na criação e legalidade dessas áreas de proteção, que, por diversas vezes, deparam-se com setores da sociedade que não compreendem a importância da criação desses espaços e têm a concepção de que desenvolvimento e conservação são opostos e que não podem ser conciliados por meio de ferramentas de planejamento e gestão ambiental, além dos mecanismos coletivos e burocráticos, inclusive para atender à legislação. Nesta perspectiva pretende-se elucidar e contextualizar as Unidades de Conservação em Sergipe, dando ênfase ao estudo da Floresta Nacional do Ibura, com seus recursos, potencialidades e histórico. O presente texto provém de estudos realizados na FLONA nos quais busca-se identificar, resgatar, investigar e elucidar seus diversos potenciais, com caráter bibliográfico/documental e observacional. Apesar de o Brasil dispor de legislação específica para tratar de seus recursos naturais, é frequente a exploração de forma inadequada, a exemplo dos recursos florestais, ocasionando diversos impactos negativos ao meio ambiente. Em Sergipe, grande parte da vegetação nativa foi desmatada para atender às necessidades socioeconômicas, restando poucos remanescentes que geralmente se encontram em áreas protegidas. Destarte, este texto também visa apresentar, de forma sucinta, as principais UCs existentes em Sergipe com ênfase na criação da UC Floresta Nacional do Ibura, em 2005, cujo plano de manejo encontra-se em processo de elaboração.

Palavras-chave: Floresta Nacional do Ibura. Recursos Naturais e Florestais. Potencial. Sergipe

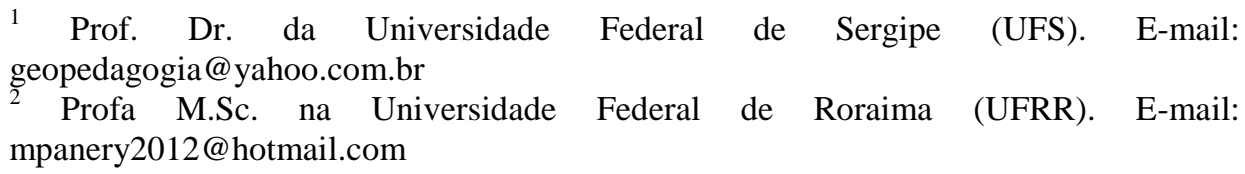




\begin{abstract}
The preservation and conservation of biodiversity require, besides the creation of legal mechanisms for collective and participatory management, actions of government, such as the creation of conservation units. In Brazil, are notorious increase of Conservation Units and extent of protected areas in recent decades, the three levels of government areas. In Sergipe, we observe a process of regularization of protected areas in order to protect areas of environmental significance and / or cultural -historical in the various ecosystems of the state, despite having the lowest percentage of strictly protected areas. There are obstacles in creating and legality of these protected areas, which, on several occasions, faced with sectors of society who do not understand the importance of creating these spaces and have the view that development and conservation are opposites and can't be reconciled through planning and environmental management tools in addition to the collective and bureaucratic mechanisms, including to comply with the legislation. In this perspective it is intended to clarify and contextualize the Conservation Units in Sergipe, emphasizing the study of Ibura National Forest, with its resources, capabilities and history. This text comes from studies in FLONA in which we seek to identify, rescue, investigate and elucidate its various potential with bibliographic / documentary and observational. Although Brazil has specific legislation to deal with their natural resources, exploitation is often inappropriately, like the forest resources, causing many negative environmental impacts. In Sergipe, much of the native vegetation has been cleared to meet the socioeconomic needs, leaving few remnants usually found in protected areas. Thus, this paper also aims to present, in summary form, the main existing PAs in Sergipe with emphasis on the creation of UC Ibura National Forest in 2005, which the management plan is being prepared.
\end{abstract}

Keywords: Ibura National Forest. Natural Resources and Forestry. Potential. Sergipe. 


\section{Introdução}

É crescente a preocupação com a degradação, preservação e depauperamento dos recursos naturais que carecem atenção consciente da sociedade civil e dos governantes, com intento de preservá-los e conservá-los.

Povos e civilizações reconheceram, ao longo da história, a necessidade de proteger áreas naturais com características especiais, pelos motivos mais distintos: estas áreas podiam estar associadas a mitos, fatos históricos marcantes e à proteção de fontes de água, caça, plantas medicinais e outros recursos naturais.

A Constituição Federal de 1988, no seu artigo 225, estabelece que o ambiente é bem de uso comum do povo, assegurando a todos o direito ao meio ambiente equilibrado, impondo ao Poder Público e à coletividade o dever de defendê-lo e preservá-lo para a presente e as futuras gerações.

Nosso país é considerado "megabiodiverso" em que se encontra uma grande variedade de espécies da fauna e da flora, compondo importantes ecossistemas que nos proporcionam um dos melhores climas do mundo, água potável pura e em grande quantidade, terras férteis e paisagens paradisíacas.

Neste sentido, o governo brasileiro protege as áreas naturais por meio de Unidades de Conservação (UC) - estratégia extremamente eficaz para a manutenção dos seus recursos a longo prazo. Para atingir esse objetivo de forma efetiva e eficiente, foi instituído o Sistema Nacional de Conservação da Natureza (SNUC), pela Lei ${ }^{\circ}$ 9.985, de 18 de julho de 2000 .

Desta feita, uma das principais estratégias para a conservação da biodiversidade é a criação de Unidades de Conservação (UC), cujo objetivo essencial é adequar o desenvolvimento socioeconômico com a manutenção da qualidade do ambiente e do equilíbrio ecológico, buscando a sustentabilidade e a geração de serviços ambientais.

Dentre os diferentes tipos de Unidades de Conservação, tem-se a FLONA (Floresta Nacional), área com cobertura florestal de espécies predominantemente nativas que tem como objetivo básico o uso múltiplo sustentável dos recursos florestais e a pesquisa científica, com ênfase em métodos para exploração sustentável de florestas nativas. 
O Brasil conta com 304 UC's federais e estima-se que haja 600 sob gestão estadual, 700 sob gestão municipal e cerca de 800 reservas particulares, totalizando aproximadamente 1,4 milhão de $\mathrm{km}^{2}$ de áreas protegidas, o que corresponde a $16,7 \%$ da área continental nacional e 1,4\% das águas jurisdicionais brasileiras (IBGE, 2005).

É mister salientar que, segundo o Ministério do Meio Ambiente e, mais especificamente no Instituto Brasileiro de Meio Ambiente (IBAMA), as Unidades de Conservação podem ser de proteção integral ou de uso indireto e de uso sustentável ou de uso direto.

As unidades de conservação de uso sustentável, ou de uso direto, são aquelas onde haverá conservação dos atributos naturais, admitida a exploração de parte dos recursos disponíveis em regime de manejo sustentável. Nestas, procura-se conciliar a preservação da diversidade biológica e dos recursos naturais com o uso sustentado de parte destes. É nesta classificação que se enquadra a Floresta Nacional do Ibura, objeto deste estudo.

As florestas nacionais foram criadas segundo a Lei n. 4.771 de 15/set/1965, sendo áreas de domínio público, providas de cobertura vegetal nativa ou plantada, estabelecidas com os objetivos de promover o manejo dos recursos naturais, com ênfase na produção de madeiras e outros produtos vegetais; garantir a proteção dos recursos hídricos, das belezas cênicas e dos sítios históricos e arqueológicos, assim como fomentar o desenvolvimento da pesquisa científica básica e aplicada da educação ambiental e das atividades de recreação, lazer e turismo (BRASIL, 2000).

Para este trabalho, priorizou-se o exame da categoria FLONA devido ao arcabouço e perspectiva que a mesma dispõe e apresenta, em caso especial, pela localidade e ao histórico de utilização dos recursos naturais pelas comunidades locais. Versa-se sobre a Floresta Nacional do Ibura, em Nossa Senhora do Socorro, Sergipe, espaço utilizado para aulas práticas, pesquisas acadêmicas e, especialmente, atividades de Educação Ambiental. Ressalta-se que o seu Plano de Manejo se encontra em fase de discussão e elaboração, atendendo os trâmites e exigências do SNUC. Trata-se de um trabalho de cunho bibliográfico, baseado em documentos legais, referenciais pertinentes à questão, a exemplo daqueles disponibilizados pelo Ministério do Meio Ambiente, IBAMA, ICMBio, Secretaria de Meio Ambiente e Recursos Hídricos de Sergipe (SEMARH) e artigos resultantes de pesquisas realizadas por diversos autores, no recorte analisado, além de constantes visitas ao local. 


\section{Delineando as Unidades de Conservação em Sergipe}

Apesar de Sergipe ser o menor Estado em extensão territorial do Brasil, com pouco menos de $22 \mathrm{mil} \mathrm{km}^{2}$, conta com grande diversidade de ecossistemas em seu território, inseridos nos biomas Caatinga e Mata Atlântica. No entanto, a forma de sua ocupação territorial levou à perda de grande parte de seu patrimônio natural.

Diversas atividades econômicas foram, e ainda são, baseadas na coleta de recursos naturais sem nenhum tipo de manejo, gerando pressão sobre a biodiversidade. Frente a este conflito, são necessárias medidas que garantam a perenidade dos recursos a fim de assegurar boas condições de vida para a atual e as vindouras gerações.

Nesse contexto, as UC's são mecanismos adequados de preservação dos recursos ambientais. A primeira unidade de conservação de Sergipe foi criada no final da década de 80, anterior a criação do (SNUC), decretado em 2000. Mesmo as criadas após a implantação do SNUC, não apresentam adequação do processo de fundação e gestão, aspectos fundamentais para o atendimento dos seus objetivos (CABRAL \& SOUZA, 2005). Isso, bem como o investimento em infraestrutura, fiscalização e monitoramento de atividades em sua área são essenciais para atingir plenamente seus objetivos.

Segundo estudos de SOUZA \& LANDIN (2007) existiam no Estado, até 2005, dez unidades de conservação: cinco estaduais: APA do Litoral Sul (1993), APA do Litoral Norte (2004), APA do Morro do Urubu (1993), APA da Foz do Rio Vaza-Barris (1990), e uma Área de Especial Proteção Ambiental (1990) um trecho do rio Sergipe, bem como suas margens, localizadas entre os municípios de Aracaju e Barra dos Coqueiros; três federais: Parque Nacional (PARNA) da Serra de Itabaiana (2005), Reserva Biológica (REBIO) de Santa Isabel (1988), Floresta Nacional (FLONA) do Ibura (1995); uma municipal, o Parque Ecológico Tramandai (1996); e, uma particular, Reserva Particular de Patrimônio Natural (RPPN) da Fonte da Bica (1999). Salienta-se que, apesar de estudos mencionarem outras unidades, como não são juridicamente legalizadas, neste texto, far-se-á um panorama baseado na classificação atual da Secretaria de Meio Ambiente e Recursos Hídricos - (SEMARH), porém, descrevem-se apenas as oficializadas.

Dentre as UC's de Sergipe, $80 \%$ foram criadas anteriormente ao estabelecimento do SNUC, sendo que grande parte apresentam irregularidades, quando analisadas de acordo com os seus critérios. Apenas as APA's do Litoral Sul, do Morro do Urubu e o PARNA da 
Serra de Itabaiana possuem diagnóstico prévio. Não existe Conselho Administrativo na maioria delas, porém o PARNA da Serra de Itabaiana é administrado pelo IBAMA e a REBIO Santa Isabel está sob responsabilidade do Projeto TAMAR. A RPPN da Fonte da Bica também possui administração, por se tratar de uma área privada (SOUZA; LANDIM 2007).

O Plano de Manejo, outra exigência do SNUC, foi concluído apenas para a APA do Litoral Sul e REBIO Santa Isabel. Entretanto, encontra-se em processo de formulação na RPPN Fonte da Bica e no PARNA da Serra de Itabaiana. Nas demais UC's sequer estão em fase de elaboração (SOUZA, B \& LANDIM, M. F, 2007, op. cit).

Apesar das dificuldades encontradas para a implantação e gestão das UC's de Sergipe, todas abrigam ecossistemas ameaçados, como restingas, manguezais e fragmentos florestais de Mata Atlântica, o que reforça a importância de medidas que garantam sua proteção, bem como estudos e pesquisas visando atender aos objetivos propostos na legislação.

Segundo informações recentes, Sergipe conta com 15 UC's, sendo quatro particulares, três federais (F), duas municipais (M) e sete estaduais (E) dentre as quais duas encontram-se em fase de recategorização (SEMARH, 2013). A seguir, delineiam-se breves considerações sobre as mesmas.

A APA Morro do Urubu (E), localizada na área urbana de Aracaju, limita-se ao Norte com o rio do Sal, ao Leste com o rio Sergipe, e ao Sul e Oeste com as áreas urbanas da zona Norte do município. Trata-se de região onde predominava a Mata Atlântica e seus ecossistemas associados. Criada e regulamentada pelos Decretos $\mathrm{n}^{\circ} 13.713$, de 16.06.93, e $\mathrm{n}^{\circ} 15.405$, de 14.07.95, a área vem sofrendo pressão urbana e se descaracterizando continuamente, estando o remanescente bastante comprometido, sobretudo pela invasão e edificação de moradias subnormais no seu entorno.

A APA Litoral Sul (E), instituída através do Decreto $n^{\circ} 13.468$ de 22 de janeiro de 1993, define a estrutura de ocupação da área compreendida entre a foz do Rio Vaza Barris e a desembocadura do Rio Real, com cerca de 55,5 km de costa e largura variável de 10 a $12 \mathrm{~km}$, do litoral para o interior. Abrange os municípios de Itaporanga d'Ajuda, Estância, Santa Luzia do Itanhy e Indiaroba e as praias mais povoadas do Estado, destacando-se Caueira, Saco e Abaís. Observam-se áreas de restingas arbóreas, manguezais e manchas preservadas de Mata Atlântica. 
A APA Litoral Norte (E), criada através do Decreto $n^{\circ}$ 22.995, em 2004, compreende aproximadamente $4752 \mathrm{~km}^{2}$, abrangendo os municípios de Pirambu, Japoatã, Pacatuba, Ilha das Flores e Brejo Grande e objetiva contribuir para o desenvolvimento socioeconômico da região, voltado às atividades que protejam e conservem os ecossistemas ou processos essenciais à biodiversidade, à manutenção de atributos ecológicos, e à melhoria da qualidade de vida da população.

O Refúgio de Vida Silvestre Mata do Junco (E), localizado em Capela, é um dos maiores remanescentes florestais do Estado, com área total aproximada de 766 ha. Criado através do Decreto 24.944 de 26 de dezembro de 2007, esta UC objetiva preservar um fragmento de Mata Atlântica, considerada um dos 34 hotspots mundiais.

O Monumento Natural Grota do Angico (E), criado pelo Decreto 24.922 de 21 de dezembro de 2007, está situado no Sertão Sergipano, entre os municípios de Poço Redondo e Canindé de São Francisco, às margens do rio São Francisco, e abriga remanescentes florestais da Caatinga. Porém, sua importância não se deve apenas a riqueza biológica, pois também possui valor histórico e cultural, com relação a trajetória do Cangaço.

O Parque Nacional Serra de Itabaiana (F) está localizado no agreste de Sergipe, abrangendo parcialmente Itabaiana, Areia Branca, Laranjeiras, Itaporanga d'Ajuda e Campo do Brito. Possui área de 7.966 ha., dos quais apenas 3,5\% estão regularizados. Seu território inclui área de transição entre Mata Atlântica e Caatinga e abriga grande variedade de fauna e flora. Administrado pelo ICMBio, é formado pelas serras Itabaiana, Comprida e Cajueiro e foi criado em 2005. Destacam-se as atividades do ecoturismo e pesquisa acadêmica.

A Reserva Biológica da Santa Isabel (F), com 5.888 ha, localiza-se nos municípios de Pirambu e Pacatuba. Criada em 1998, abriga uma das bases do Programa Brasileiro de Conservação das Tartarugas Marinhas (TAMAR) e tem o objetivo de proteger o maior sítio reprodutivo da espécie Lepidochelys olivacea (Tartaruga oliva) no Brasil. Sob direção do ICMBio, é o responsável pela preservação dos ecossistemas costeiros da Reserva, compostos principalmente por dunas, restingas, manguezais e lagoas.

As Reservas Particulares de Proteção Natural (RPPN), devido a escassez de informações, estudos e definições legais, são apenas mencionadas: Fonte da Bica, Bom Jardim, Tapera, Marinheiro, Pedra, bem como os 
parques municipais Tramandai em Aracaju e Lagoa do Frio em Canindé de São Francisco.

Em fase de recategorização, encontram-se as APA's do rio Sergipe e a foz do rio Vaza Barris, instituídas em 1990. A primeira, definida como "Paisagem Natural Notável" e área de especial proteção ambiental, abrange todo o trecho do rio Sergipe, na divisa dos municípios Aracaju e Barra dos Coqueiros, compreendendo suas margens e leito. A segunda abrange as áreas de proteção ambiental da foz do Rio Vaza-Barris, e compreende as Ilhas do Paraíso e da Paz localizadas respectivamente na foz do Rio Vaza-Barris e na foz do Rio Santa Maria, em frente ao Povoado Mosqueiro.

Quanto a Floresta Nacional do Ibura, será detalhado a seguir.

\section{De Posto Zootécnico à Floresta Nacional do Ibura}

Em 1917, o poder público estadual adquiriu uma área da fazenda Ibura, no Povoado Estiva, em Nossa Senhora do Socorro/SE, com cerca de 150 hectares, que abrigava campos de pastagens e culturas de plantas forrageiras, para apoiar o desenvolvimento da pecuária no Estado de Sergipe. O Posto Zootécnico de Ibura, com estrutura física para o desenvolvimento de pesquisas, controle de zoonoses e sede de estação meteorológica ${ }^{3}$ foi instalado para funcionar em maio do ano supracitado, segundo decreto estadual de 10 de março de 1917.

O referido posto realizava também aplicação em seu rebanho de diversas vacinas, em caráter experimental advindas do "Instituto Oswaldo Cruz", atualmente bastante conhecidas e utilizadas pelos criadores. Os reprodutores do Posto eram de diversas raças ${ }^{4}$.

Em 1933, o Ministério da Agricultura e o Serviço de Fomento de Produção Vegetal foram reorganizados e foi criada uma Seção de Reflorestamento. Nessa época criam-se dois Hortos Florestais o do Ibura, em Sergipe e o de Lorena, em São Paulo (MARTINI, 2004).

\footnotetext{
3 O posto prestava serviços a União, fornecendo dados meteorológicos para o observatório nacional, diários por telegrama, enviados mensalmente através de mapa completo, (SILVA, 1920 p.98).

${ }^{4}$ Os reprodutores eram das raças: bovina, Holandesa, Flamenga, Jersey, South-Devon, Hereford e Limousine; Suína; Large Blach e Berkshire, e Asinina; Andaluza. Segundo Silva (1920, p97).
} 
Nas décadas de 60 e 70, o Horto Florestal do Ibura foi uma das maiores atrações de lazer de Sergipe, principalmente para a população instalada nas suas proximidades. Em 1986, foram produzidas cerca de $50 \mathrm{mil}$ mudas de espécies nativas que eram distribuídas para órgãos públicos, entidades de pesquisa e instituições de cunho filantrópico, gratuitamente. (INFORM RURAL, 1986).

Nessa época, o Horto do Ibura era um Posto de Fomento Florestal (POFOM), possuindo infraestrutura de moradia para os funcionários mais graduados, administrado pelo extinto Instituto Brasileiro de Desenvolvimento Florestal (IBDF). Em fevereiro de 1989, foi criado o Instituto Brasileiro de Recursos Naturais Renováveis (IBAMA), Lei $\mathrm{n}^{\circ}$ 7.735/89, como novo órgão central para o meio ambiente e os recursos naturais renováveis que na sua estrutura não contemplou a categoria de POFOM.

Em 19 de setembro de 2005, o Governo Federal decretou a criação da Floresta Nacional do Ibura, com área superior a 144 mil ha. Com esta aquisição, o país passou a contar com 70 Florestas Nacionais, totalizando mais de 18,5 milhões de hectares sobre a administração do IBAMA (SILVA, 2007)

A FlONA Ibura foi criada com os objetivos de promover o uso múltiplo sustentável dos seus recursos florestais, a manutenção de banco de germoplasma in situ de espécies florestais nativas, inclusive do bioma Mata Atlântica que conta com formações de floresta estacional semidecidual nos estágios médio e avançado de regeneração, em associação com manguezais, a manutenção e a proteção dos recursos florestais e da biodiversidade, a recuperação de áreas degradadas e a pesquisa científica (Figura 1). 

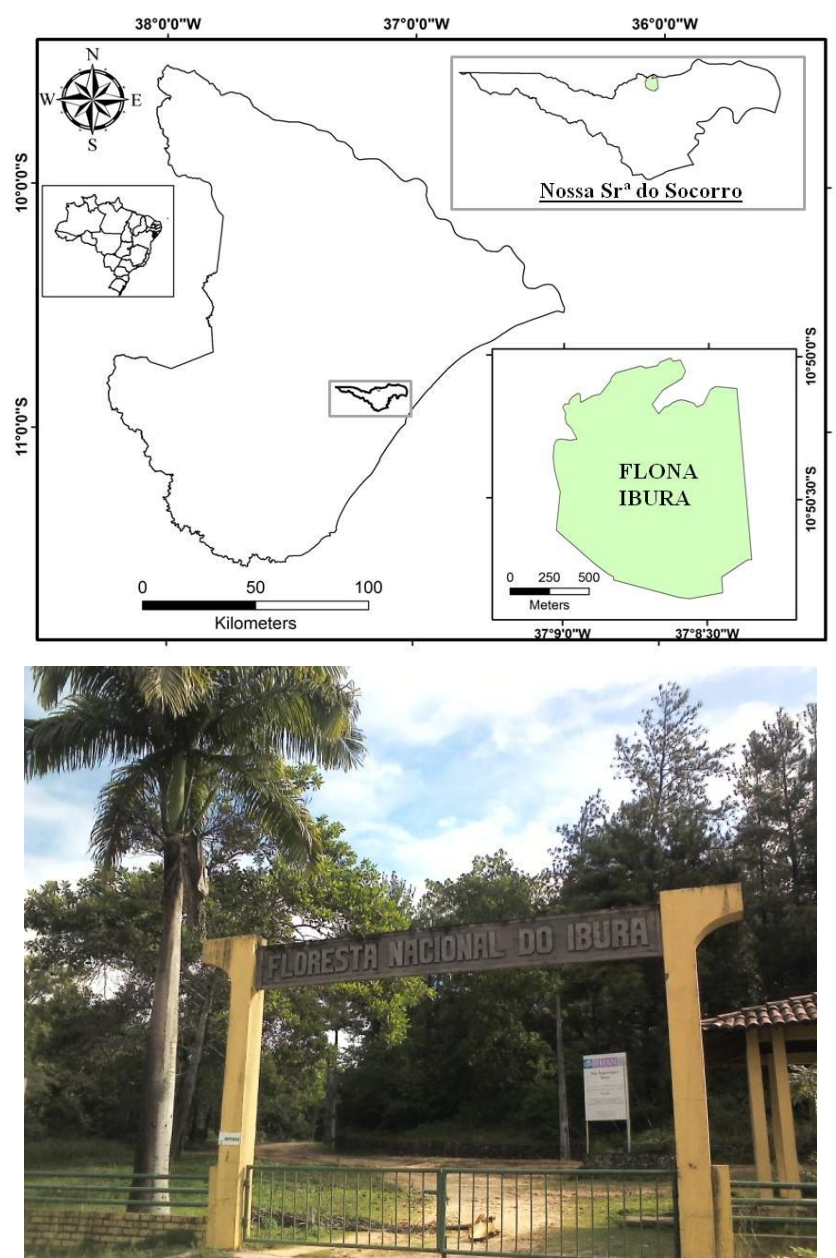

Figura 1. Floresta Nacional do Ibura. A. Localização. Autor: Patrício Adriano da Rocha.

B. Portal de Entrada. Autor: Carlos Alberto Vasconcelos

\subsection{Diversos usos e potencialidades da Flona do Ibura}

A referida FLONA destaca-se pela diversidade de potencialidades, dentre estas, dos recursos hídricos inclusos na sub-bacia hidrográfica do rio Cotinguiba com nascentes originárias do aquífero Sapucari situado em seu subsolo, abrigando importante manancial, que segundo dados da Companhia de Saneamento de Sergipe, disponibiliza mais de 25.000 $\mathrm{m}^{3} /$ dia de água, atendendo à demanda parcial de Aracaju e Nossa Senhora do Socorro, beneficiando mais de 100 mil pessoas. Deste modo, nota-se a importância do uso indireto da biodiversidade, sobretudo quando considerada a proteção da cobertura vegetal para a manutenção dos mananciais (SILVA, C. E; PINTO, J. B.; GOMES, L. J. 2008).

Pesquisa realizada nas comunidades do entorno, Porto Grande, Tabocas e Estiva, constatou os seguintes usos da área: água para abastecimento doméstico, lenha, meio de acesso, pesca de peixes e mariscos, plantas 
medicinais, frutos, plantio de roçado, sanitário, caça, coleta de sementes e galhos para artesanato (SILVA et al, 2004).

Informações sobre a diversidade botânica principalmente em estudo realizado por Santos (2001) indica que a cobertura vegetal do Ibura está representada por: $81 \%$ de mata atlântica, $6 \%$ manguezal, $9 \%$ de bosques de eucaliptos e $4 \%$ pastagem. Estudos fitossociológicos constataram entre as espécies vegetais de maior ocorrência remanescentes da Floresta Estacional Semidecídual, registradas como: Fagara sp, Byrsonima sericea e Tapirira guianensis, sendo a primeira, endêmica da Mata Atlântica. No manguezal, destaca-se a Laguncularia racemosa (mangue branco), a qual é dominante (ENTAL, 2001).

Sabe-se que a fragmentação das formações florestais nativas de Sergipe, no século passado, foi intensa, uma vez que a cobertura vegetal da Mata Atlântica já representou $40 \%$ da cobertura vegetal do Estado e hoje resta cerca de $1 \%$ da sua cobertura original, sob forma de manchas descontínuas.

Para o entendimento dos mecanismos que promovem a recuperação florestal, são importantes as investigações sobre a estrutura e a dinâmica dos fragmentos remanescentes. Deve existir o conhecimento da composição florística e da fitossociologia, bem como a caracterização dos fatores que influenciam tais diferenças, dentre os quais se destacam as características fenológicas das espécies, as condições microclimáticas e edáficas e as fontes de propágulos. Também pesquisas sobre a dinâmica da regeneração natural são essenciais para a elaboração correta dos planos de manejo e tratamento silvicultor, permitindo um aproveitamento racional e permanente dos recursos florestais.

Em estudo realizado por CRUZ, (2008) sobre a Flona do ibura, detectouse que as espécies Byrsonima sericea, Tapirira guianensis e agara sp., foram as que mais se destacaram com potencial de regeneração. Já as famílias que obtiveram maior valor de importância foram: Malpighiaceae, Anacardiaceae, Rutaceae, Caesalpinaceae, Rubiaceae. O referido estudo também mostra que vem ocorrendo um processo de regeneração natural no sub-bosque de Eucalyptus sp., tendo em vista que o mesmo não impediu o estabelecimento de espécies nativas.

Neste sentido, o processo de regeneração natural é de fundamental importância para se determinar a capacidade de estabelecimento das espécies na comunidade vegetal (MELO et al, 2004).

$\mathrm{Na}$ verdade, não se tem ainda estudos aprofundados sobre a importância econômica dos recursos florestais da área. Porém, o diagnóstico 
socioambiental realizado pelo IBAMA, juntamente com o Departamento de Agronomia da Universidade Federal de Sergipe, (2010) revelaram nas entrevistas com as comunidades do entorno do Ibura, que o extrativismo faz parte do cotidiano, sobretudo do Povoado Estiva, como fonte de subsistência, principalmente para lenha, matéria prima para artesanato e frutos. Além disso, foram relatados que moradores retiram, ilegalmente, estacas e madeiras para uso na construção e reforma de residências http://www4.icmbio.gov.br/flonas/index.php?id_menu=219.

Atendendo aos objetivos da FLONA, segundo a (Lei Federal $n^{\circ}$ 9.985, de 18/07/2000), há atualmente na floresta nacional do Ibura uma sementaria com produção de mudas de plantas nativas da Mata Atlântica para recuperar áreas degradadas, inclusive em todo o estado; um minhocário utilizado para adubação e está em processo de consolidação um centro de recuperação de animais silvestres.

A fauna do Ibura caracteriza-se por apresentar poucos endemismos, com espécies de ampla distribuição no Nordeste, estando alterada do seu estado original por ter sido utilizada como área de soltura de animais silvestres, o que não diminui a importância da conservação da área, pois muitas destas espécies encontram aí o seu refúgio.

Apesar de a fauna ser escassa em função da pequena área e por estar circundada por rodovias (BR 101 e SE 090) caracteriza-se por apresentar poucos endemismos, onde as espécies ali encontradas têm ampla distribuição geográfica no Estado e no Nordeste, estando alterada do seu estado original por ter sido utilizada como área de soltura de animais silvestres, o que não diminui a importância da conservação da área, pois muitas destas espécies acham aí o seu refúgio.

Quanto à situação fundiária, deve ser destacado que o Ibura, além de se constituir em uma área pertencente à União, não possuía posseiros ou invasões no seu interior, o que contribuiu para agilizar o processo de criação da Flona.

A ocupação da terra no entorno, além das comunidades Porto Grande, Estiva, Tabocas e sede do município, está representada por canaviais e pastagens e instalados dois postos de combustíveis, indústrias têxtil (Santista S/A) e extrativistas, representadas pelas fábricas de cimento do grupo Itaguassu Agroindustrial S/A, Cimento de Sergipe S.A., do grupo Votorantim. Nos arredores, tem-se ainda a instalação de um gasoduto da Petrobras. 
Ressalta-se a descoberta de artefatos de pedra lascada nas estradas internas da Flona no início de 2008. O que permitiu, a partir da visita de arqueólogos, a criação do Sítio arqueológico Ibura que está sendo analisado pelo IPHAN, bem como de explorações espeleológicas.

Desta feita, estudos recentes para caracterização do meio físico, realizados pela Gerência Executiva do IBAMA em Sergipe, Universidade Federal de Sergipe e Embrapa/SE, apontaram as seguintes ocorrências: 123 espécies vegetais nativas de valor econômico, ecológico e cultural na área, entre elas o angelim, aroeira, sucupira, ingá, jacarandá, jatobá, jenipapo; fauna bastante diversificada com 5 espécies de anfíbios, 13 de répteis em especial o lagarto teiú, a cobra coral, cobra-verde, jararaca; 56 de aves e 14 de mamíferos, destacando-se a cutia. Pássaros como canção, cardeal, jandaia-da-caatinga, galo-de-campina e sofrê. Entre as espécies da fauna aquática, duas estão em risco de extinção o cavalo-marinho e o mero (CRUZ, 2008).

Pelos seus atributos ambientais, aliados ao fato de dispor de infraestrutura viária, predial e de redes d'agua, energia elétrica, facilidades de acesso e comunicação, a área apresenta condições apropriadas para a implantação e realização de atividades inerentes a uma Flona, inclusive com práticas de Educação Ambiental e Ecoturismo, demonstrando o potencial de transformação das comunidades locais da região em sociedades sustentáveis.

\section{Considerações Finais}

Diante do explicitado, pretende-se de maneira breve elucidar pontos importantes, sintetizando a temática abordada. Adianta-se que muito se tem por fazer, principalmente em termos de cumprimento da legislação por parte dos governantes, conscientização da população próxima às Unidades de Conservação que de forma direta ou indireta tem contatos com os recursos naturais e animais, de modo específico oriundos da Floresta Nacional do Ibura.

A Secretaria Estadual do Meio Ambiente e dos recursos Hídricos (SEMARH) tenta fazer cumprir os objetivos das Unidades de Conservação, fazendo a implantação do seu conjunto de UCs, com a recategorização daquelas unidades conflitantes com a legislação vigente.

O processo de transformação da área em FLONA foi um desafio para a comunidade, pois quando a questão ambiental é colocada em discussão, passa por atores sociais que possuem diferentes concepções de meio Revista Ambiralências •ISSN 2318-3888• V1 • N.2・p. 129-144• Jul-Dez/2013. 
ambiente e, consequentemente, por suas diferentes posturas diante do ambiente em que vivem. Porém, nem sempre a sociedade está pronta para responder tal demanda (SILVA, 2007).

Atualmente, está em fase de elaboração o plano de manejo da Unidade baseados fundamentalmente, nas seguintes premissas: Orientações dispostas no "Roteiro Metodológico para elaboração de Plano de Manejo para Florestas Nacionais" (ICMBio, 2009); Lei no 9.985 de 18 de julho de 2000 que institui o Sistema Nacional de Unidades de Conservação da Natureza (SNUC) e Decreto $\mathrm{n}^{\circ} 4.430$ de 22 de agosto de 2002 que regulamenta o SNUC; Decreto $n^{\circ} 1.298$, de 27 de outubro de 1994, que aprova o regulamento das Florestas Nacionais; Conhecimento atual da Floresta Nacional de Ibura, Diagnóstico; Discussões e conclusão da Oficina do Pesquisador - OPE e Orientações do Planejamento Estratégico para a Gestão para Resultados.

Finalizando, é necessária a avaliação das Unidades de Conservação em Sergipe, a fim de verificar suas condições de adequação ao SNUC, bem como a eficiência das mesmas nos fins a que se propõem.

\section{Referências}

BRASIL. Lei $n^{\circ}$ 9.985, de 18 de julho de 2000. Institui o Sistema Nacional de Unidades de Conservação - SNUC. Disponível em <www.planalto.gov.br/ccivil_03/Leis/L9985.htm >. Acessado em 08 de agosto de 2013

CABRAL, N. R. A. J.; SOUZA, M. P. Áreas de proteção ambiental: planejamento e gestão de paisagens protegidas. 2 ed. São Carlos: RIMA, 2005 .

CRUZ, E. S. Florística e fitossociologia de espécies nativas em subbosque de eucalyptus sp. na floresta nacional do Ibura/SE. São Cristóvão, 2008. Monografia (Curso de Engenharia Florestal) - Núcleo de Engenharia Florestal, Universidade Federal de Sergipe.

ENTAL. Relatório de impacto ambiental do aterro sanitário da grande Aracaju. Aracaju: ENTAL, Tecnologias Geológicas e ambientais Ltda. 2001.

GONÇALVES, A. R; FERNANDES, C. H. V \& VELOSO, V. S (Orgs,). Roteiro metodológico para elaboração de planos de manejo de florestas nacionais. Brasília: ICMBio, 2009. 
IBAMA. Relatório de vistoria técnica: estudos e levantamentos prévios para criação de floresta nacional - MMA/IBAMA/SE- 11 de janeiro de 2005.

IBGE. Instituto Brasileiro de Geografia e Estatística. Perfil dos municípios brasileiros: meio ambiente 2002. Rio de Janeiro: IBGE, 2005. Disponível em: http://www.ibge.gov.br/home/estatistica/economia/perfilmunic/meio_am biente_2002/default.shtm

INFORM RURAL. Horto florestal: a Natureza Relegada ao Esquecimento. Aracaju. Outubro de 1986. Ano I. N ${ }^{0}$ 1. p.18-19.

MARTINI, A. J. O plantador de eucaliptos: a questão da preservação florestal no Brasil e o resgate documental do legado de Edmundo Navarro de Andrade. São Paulo, 2004. Dissertação (Mestrado em História Social). Programa de Pós-Graduação em História Social, Faculdade de Filosofia, Letras e Ciências Humanas, Universidade de São Paulo.

MELO, F. P. L., AGUiAR NETO, A. V., SMABUKURO, E. A. \& TABARELLI, M. Recrutamento e Estabelecimento de Plântulas. In: Ferreira, A. G., \& Borghetti, F. (orgs.) Germinação: do Básico ao Aplicado. Porto Alegre: Artmed, p. 236 - 249, 2004

SANTOS, E. B. Influência associada da cobertura vegetal e solo sobre qualidade dos mananciais hídricos do Horto do Ibura. São Cristóvão, 2001. Monografia (Especialização em Gestão de Recursos Hídricos e Meio Ambiente) - Departamento de Agronomia, Universidade Federal de Sergipe.

SERGIPE. SEMARH. Secretaria de Estado do Meio Ambiente e dos Recursos Hídricos. Áreas Protegidas, Biodiversidade e Florestas. Disponível em

http://www.semarh.se.gov.br/biodiversidade/modules/tinyd0/index.php?i $\mathrm{d}=11>$ Acessado em 20/06/2013.

SILVA, C. $M$ et al. Usos do horto florestal do Ibura pelas comunidades locais. In: VI CONGRESSO DE INICIAÇÃO CIENTÍFICA PIBIC-CNPQ/UFS, 2004. Resumos..., São Cristóvão. Programa Institucional de Bolsas de Iniciação Científica, Conselho Nacional de Desenvolvimento Científico e Tecnológico. 2004.

SILVA, C. S. Álbum de Sergipe: 1534 - 1920. Aracaju/SE s.n., 120

SILVA, L. P. Participação comunitária na construção de uma unidade de conservação: o caso do horto florestal do Ibura, município de Nossa Senhora do Socorro/SE. Cadernos Atlântico de PósGraduação, v.1, n. 1, 2007. 
SILVA, C. E; PINTO, J. B. \& GOMES, L. J. Ecoturismo na Floresta Nacional do Ibura como potencial fomento de sociedades sustentáveis. Revista Nordestina de Ecoturismo, v. 1, n.1. ISSN: 19838344 - Seção: Artigos. Aracaju, 2008.

SOUZA, B. \& LANDIM, M. F. Unidades de conservação no estado de Sergipe: Análise do quadro atual. Anais do VIII Congresso de Ecologia do Brasil, 23 a 28 de Setembro de 2007, Caxambu - MG 